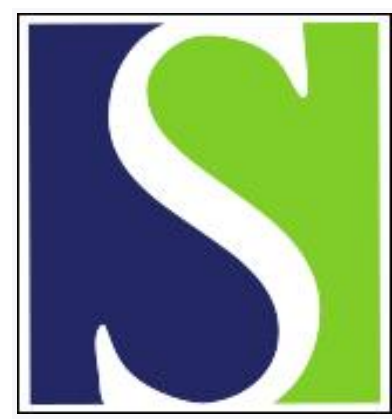

Scand J Work Environ Health 2013;39(2):170-177

https://doi.org/10.5271/sjweh.3323

Published online: 24 Sep 2012, Issue date: 01 Mar 2013

Breast cancer among shift workers: results of the WOLF longitudinal cohort study

by Knutsson A, Alfredsson L, Karlsson B, Åkerstedt T, Fransson El, Westerholm $P$, Westerlund $\mathrm{H}$

This cohort study showed that shift work with night shifts is associated with increased risk of breast cancer, but not shift work without night shifts. Research on the disease mechanisms needs to be intensified.

Affiliation: Department of Health Sciences, Mid Sweden University, SE-85170 Sundsvall. Sweden. Anders.Knutsson@miun.se

Refers to the following texts of the Journal: 2010;36(2):163-179

2012;38(4):380-390 2010;36(2):134-141 2002;28(4):238-248

2007;33(5):336-343

The following articles refer to this text: 2013;39(5):431-447;

2014;40(3):295-304; 2014;40(5):502-510

Key terms: breast cancer; cancer; chronodisruption; circadian rhythm; cohort study; Cox regression; melatonin; neoplasm; night work; shift work; shift worker; WOLF

This article in PubMed: www.ncbi.nlm.nih.gov/pubmed/23007867

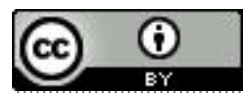




\title{
Breast cancer among shift workers: results of the WOLF Iongitudinal cohort study
}

\author{
by Anders Knutsson, MD, ${ }^{1}$ Lars Alfredsson, PhD, ${ }^{2}$ Berndt Karlsson, MD, ${ }^{3}$ Torbjörn Åkerstedt, PhD, ${ }^{4}$ \\ Eleonor I Fransson, PhD, ,2, 5 Peter Westerholm, MD, ${ }^{6}$ Hugo Westerlund, PhD ${ }^{4}$
}

\begin{abstract}
Knutsson A, Alfredsson L, Karlsson B, Åkerstedt T, Fransson El, Westerholm P, Westerlund H. Breast cancer among shift workers: results of the WOLF longitudinal cohort study. Scand J Work Environ Health. 2013;39(2):170-177. doi:10.5271/sjweh.3323
\end{abstract}

\begin{abstract}
Objective The aim of this study was to investigate whether shift work (with or without night work) is associated with increased risk of breast cancer.

Methods The population consisted of 4036 women. Data were obtained from WOLF (Work, Lipids, and Fibrinogen), a longitudinal cohort study. Information about baseline characteristics was based on questionnaire responses and medical examination. Cancer incidence from baseline to follow-up was obtained from the national cancer registry. Two exposure groups were identified: shift work with and without night work. The group with day work only was used as the reference group in the analysis. Cox regression analysis was used to calculate relative risk.

Results In total, 94 women developed breast cancer during follow-up. The average follow-up time was 12.4 years. The hazard ratio for breast cancer was 1.23 [95\% confidence interval (95\% CI) 0.70-2.17] for shifts without night work and 2.02 (95\% CI 1.03-3.95) for shifts with night work. When including only women $<60$ years of age, the risk estimates were 1.18 (95\% CI 0.67-2.07) for shifts without night work, and 2.15 (95\% CI 1.10-4.21) for shifts with night work.
\end{abstract}

Conclusions Our results indicate an increased risk for breast cancer among women who work shifts that includes night work.

Key terms chronodisruption; circadian rhythm; Cox regression; melatonin; neoplasm; night work; shift work.

The prevalence of odd work hours has increased during the last decades in Europe and many other countries (1). According to the last survey in Europe, $17 \%$ and $10 \%$ of workers do shift and night work, respectively. In addition, $53 \%$ work at the weekend, and $20 \%$ work on call (2). Shift work is associated with many health problems like sleep disorders, fatigue, accidents, cardiovascular disease, gastrointestinal disorders, and cancer (3). In 2007, the International Agency for Research on Cancer (IARC) (4) concluded that "shiftwork that involves circadian disruption is probably carcinogenic to humans". The IARC review further stated that the association between shift work and breast cancer was supported by sufficient evidence among experimental animals but only limited evidence in epidemiological studies on humans. Regarding cancer, shift work has been associated with breast cancer $(5,6,7)$, prostate cancer (8), endometrial cancer (9), colorectal cancer (10), and Non-Hodgkin's lymphoma (11). The most extensively studied cancer in this context is female breast cancer. In a recent review, nine epidemiological studies were reported, of which six were positive (12). Since then, an additional four studies have been published (13-16), three of which were positive.

Nearly all living organisms have adapted to the 24-hour alternating pattern of days and nights. This

1 Department of Health Sciences, Mid Sweden University, Sundsvall, Sweden.

2 Institute of Environmental Medicine, Karolinska Institutet, Stockholm, Sweden.

3 Clinic of Occupational and Environmental Medicine, Norrlands University Hospital, Umeå, Sweden.

4 Stress Research Institute, Stockholm University, Stockholm, Sweden.

5 School of Health Sciences, Jönköping University, Jönköping, Sweden.

6 Occupational and Environmental Medicine, Uppsala University, Uppsala, Sweden.

Correspondence to: Anders Knutsson, Department of Health Sciences, Mid Sweden University, SE-85170 Sundsvall. Sweden. [E-mail: Anders.Knutsson@miun.se] 
endogenous, circadian rhythm is entrained to the individual's environment by light stimulus through the eyes. The master clock, which is located in a paired suprachiasmatic nucleus (SCN) in the hypothalamus, helps the organism to adjust to the environmental 24-hour cycles.

Present in all organs of the human body, clock cells have the ability to create an endogenous biological rhythm. The peripheral clock cells, located outside the hypothalamus are influenced by the SCN clock, but they are also entrained by the timing of food intake. The clock cells have specific clock genes that create a circadian rhythm by means of a cyclic production of specific proteins.

Clock genes take part in crucial functions of cell biology, eg, cell proliferation (17), DNA repair (18), and apoptosis (19). The cell division is temporally regulated, and this rhythmic control affects the rate of the DNA replication (20). In experimental studies on rodents, it has been shown that eradication of the SCN leads to disturbance of the circadian rhythm and increases the growth of malignant tumors (21). Exposure to light at night (LAN) has a similar effect on the circadian system (22). Animal experiments have demonstrated that LAN accelerates the growth of breast cancer cells (23). A recent epidemiological study on women with experience of long-term night shift work showed that shift work was associated with epigenetic changes of the clock genes CLOCK and CRY (24). The same epigenetic changes have been observed in breast cancer case-control studies (25).

Melatonin is a chronobiotic hormone produced by the pineal gland that transmits information on environmental darkness and lightness to the body (26). Melatonin has anticarcinogenic actions that are mediated by a number of mechanisms, including antioxidant and antimitotic activity $(26,27,28)$. In addition, melatonin has antiestrogenic properties. Since estrogen promotes growth of breast cancer cells, deficiency of melatonin stimulates their growth (27). Melatonin is manufactured and secreted mainly during the night. If the individual is exposed to LAN, the production of melatonin decreases acutely. Depending on the time when LAN occurs, it can also shift the phase of melatonin in blood.

Erren \& Reiter (29) have suggested the following definition of circadian disruption or chronodisruption: "a breakdown of phasing internal biological systems appropriately relative to the external, ie, environmental changes, which leads to chronobiological disorders" (29). They also suggest that the best markers today of chronodisruption are melatonin or its metabolites in saliva, urine, and blood, and observational surrogates such as work at unusual times and/or unusual sleep patterns. As concerns shift work, shifts including night work are supposed to be the strongest chronodisruptor. The reason for this is that night work apparently is associated with exposure to LAN. However, studies on people working night shifts have not yielded consistent results with respect to melatonin levels (30-33). Maybe, the mean level of melatonin is not as important as the amplitude of the curve or the phase shift. Exposure to LAN will shift the melatonin acrophase forward if the subject is exposed in the late evening or early night. If the exposure is present in the early morning, the shift of the acrophase will be backward. Thus, it is a possible that not only night shifts but also late evening or early morning shifts can have chronodisruptive properties. We are aware of only two published studies reporting the risk of breast cancer in relation to shift work without night shifts. None of those showed increased risk among the shift workers $(34,15)$. There is a need for more studies comparing the risk of breast cancer in relation to different shift systems, also systems that do not include night work. The aim of the present study was to compare the risk of breast cancer among women with day work and shift work with and without night shifts.

\section{Methods}

The data were obtained from the WOLF (Work, Lipids, and Fibrinogen) occupational cohort study that included subjects who were employed in different public and private companies (35). The baseline study was first carried out in Stockholm, Sweden, from 1992-1995 (WOLFS, $\mathrm{N}=5698$ ). In order to include more subjects, who worked in blue-collar jobs, a new data collection was carried out in two counties in the north of Sweden from 1996-1997 (WOLFN, N=4718). All subjects were employed at baseline (aged 19-70 years) and worked in 60 different companies. The major branches were the pharmaceutical industry, transportation, public administration, telecommunication, sales work, schools, the paper and pulp industry, banks, offices, and the mechanical industry. The overall participation rate was around $80 \%$. The subjects who participated in the 1996-1997 data collection were invited to a follow-up examination, which was performed during 2000-2003 (WOLFF, N=5433). Of those, 3630 were re-examined, and 1803 were recruited for the first time. In the present analysis, we included all women who entered the cohort in 1992-1995, 1996-1997, and 2000-2003, in total 4087 employees. Among those, it was possible to classify exposure to shift and day work among 4036 women, comprising the analytic sample for this study.

At baseline, the participants answered a questionnaire (at home) and were examined by nurses at 33 occupational health units. The questionnaire was extensive and contained questions about work tasks, occupation, work hours, education, work environment, stress, behavioral factors, family, physical activity, 
sleep, health, pharmaceuticals, hereditary issues, and foreign extraction. The medical examination included measurement of height, weight, abdominal circumference, hip circumference, and blood pressure. The nurses, who performed the examination, were trained beforehand to ensure standard procedure.

A new questionnaire was sent to all participants in 2009. In total, 2148 women answered the questionnaire in 2009 (WOLFU). Figure 1 shows the flow chart in the present study.

\section{Shift work}

The two following questions were included in the WOLFS (1992-1995) and WOLFN (1996-1997) questionnaires: (i) "Do you work shifts?" Possible responses: (a) no; (b) 2 shifts; (c) 3 shifts with continuous operation; (d) according to a rota (irregular scheduling or working hours round the clock and over the whole week according to a particular work schedule; (e) other type of shift. (ii) "How many hours do you normally work per week including overtime, and how are these hours distributed on average?" Possible responses: (a) day work (06:00-18:00 hours), number of hours $=x x$; (b) evening work (18:00-22:00 hours), number of hours $=x x$; (c) night work (22:00-06:00 hours), number of hours $=x x$.

In the WOLFF questionnaire (2000-2003), the questions were similar but the response options to question (i) were changed to: (a) no; (b) 2 shifts; (c) 3 shifts with continuous operation; (d) according to a rota without night shifts (irregular scheduling or working hours round the clock and over the whole week according to a particular work schedule); (e) according to a rota with night shifts; (f) permanent night work; and (g) other type of shift.

In addition, the WOLFF questionnaire asked if the respondent had changed shift system during the last five years - either from shift to day or vice versa.

In the WOLFU questionnaire in 2009, the following questions were asked: (i) "Which option is best suited in terms of your current working hours? If you are not employed right now we want you to think of the time just before you stopped working?" (a) day work (about 06:00-18:00 hours); (b) evening work (about 18:00 22:00 hours); (c) night work (about 18:00-06:00 hours); (d) shift work, not night; (e) shift work, including night; (f) according to a rota (ie, working hours according to a particular work schedule), not night; (g) according to a rota (ie, working hours according to a particular work schedule), including night; (h) other working hours. (ii) "Over how many years of your career have you worked shifts? If you have never worked shifts, enter 0 years." (iii) "How many years have included night work? If you have never worked shifts with night work, indicate the last year you worked shifts, and enter 0 years."
In order to categorize the participants in three groups (ie, day work and shift work with and without night shifts), we used data from baseline, followup in 2000-2003 (WOLFF), and follow-up in 2009 (WOLFU). If data indicated day work on all occasions when the subject participated, she was regarded as a day worker. If data indicated shift work without night work on $\geq 1$ occasion, and day work for the rest, the participant was defined as a worker with shift work without night work. If the data indicated shift work with night work on $\geq 1$ occasion, and day work or shift work without night for the rest, the participant was regarded as a worker with night shift work. Information on shift/day work was obtained from 1459 participants from baseline only. In total, 2148 subjects participated in baseline and WOLFU, and 429 subjects participated on all three occasions (WOLFN or WOLFS, WOLFF and WOLFU).

\section{Breast cancer}

Data on cancer incidence were obtained from the Swedish cancer registry from its establishment in 1958 to 2008. Reporting is mandatory and covers the total population (36). It includes individual data on personal identification number, sex, place of residence, site of tumor, histological type, basis and date of diagnosis, date and cause of death, date of migration, and whether a patient was registered as a resident in Sweden at the end of a specific year. However, cases without a cancer notification, but reported to the Cause of Death Register, are not included. Breast cancer codes according ICD-7 (170) or ICD-10 (C50) were used to define incident breast cancer cases. The date and causes of death were obtained from the Swedish death registry between 1992-2008. Women who developed breast cancer between 1958 and baseline were excluded from the analyses $(\mathrm{N}=10)$. All deceased women with breast cancer as an underlying cause in the death certificate $(\mathrm{N}=8)$, were included in the Swedish cancer registry in the present study.

\section{Covariates}

Information on the following potential confounders was collected at baseline: anthropometric variables (height, weight, waist and hip circumference) were measured, and information about educational level, number of children, smoking, menopausal status, oral contraceptive use, hormones other than contraceptives, alcohol intake, and educational level was obtained from the questionnaire. Body mass index (BMI; weight in kilograms/ height in square meters), and waist-hip ratio (waist/hip in centimeters) were calculated based on the anthropometric measures. 


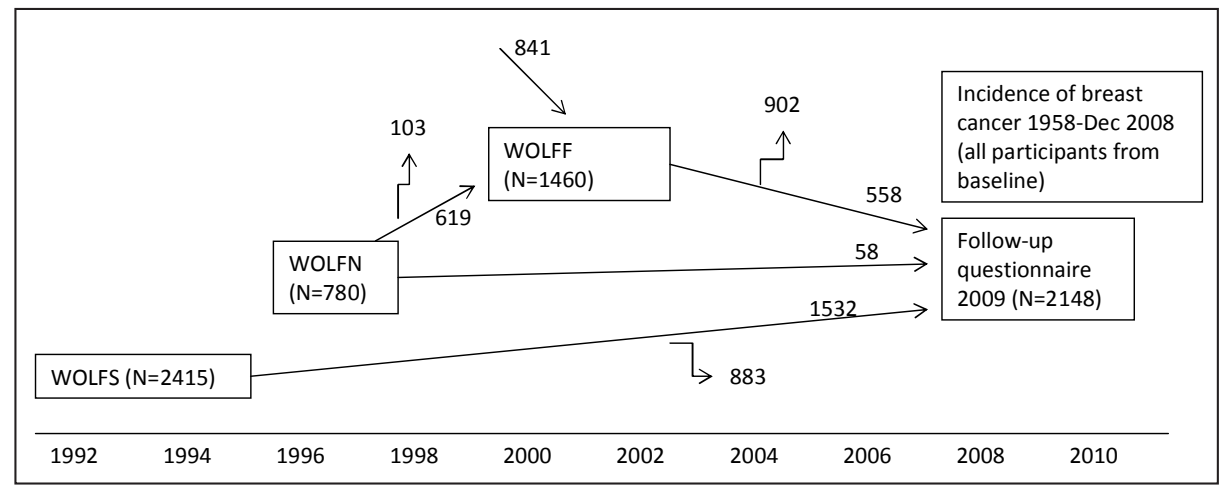

Figure 1. A flowchart for description of the WOLF cohort. WOLFS= WOLFStockholm; WOLFN=WOLF Norrland; WOLFF=follow-up of WOLFN and new recuitment to WOLFN

\section{Statistical analysis}

All statistical analyses were performed using SPSS/Windows, version 17.0 (SPSS Inc, Chicago, IL, USA). The results are expressed as percentages for dichotomous variables and means for continuous variables. Chi-square test was used for categorical variables. Number of children was tested by Mann Whitney U-test (due to a skewed distribution). Two-tailed tests were used. Cox regression analysis was used for multivariable analysis. Hazard ratios (HR) are expressed with $95 \%$ confidence intervals $(95 \%$ $\mathrm{CI})$. Attained age was used as time variable (37). When restricting the population to $<60$ years of age, censoring was done for time of death, time of diagnosis or when the subject reached age 60 , whichever came first. The working time variable was categorized into day work and shift work with and without night work. Day work was used as reference. The following were potential confounding variables from baseline: (i) body mass index (BMI) (continuous); (ii) waist-hip ratio (continuous); (iii) educational level dichotomized in two ways: educ1 (coded 1 for university or college, coded 0 for lower than university/college education), educ2 (coded 1 for high school or higher level, coded 0 for lower level than high school); (iv) current smoking (current versus not current smoker); (v) ever smoker (ever versus never smoker); (vi) menopausal status, and (v) treatment with hormones other than oral contraceptives. The variable "number of children" was categorized into four categories: $0,1,2, \geq 3$ children. Alcohol intake was based on the question "On average how many alcoholic beverages have you imbibed during the past 12 months? Indicate with a cross how often and specify how much." A new variable was calculated that was dichotomized. High level of alcohol intake was defined as consumption of alcoholic beverages (beer, wine or liquor) on average $\geq 6$ times per week. Low level was defined as less than that. All variables were not kept in the main model because they only marginally influenced the HR. Therefore, the final model included only exposure to day/shift work, number of children and alcohol intake.

\section{Results}

The mean follow-up time (time from baseline to censorship) was 12.4 years (range $0.2-16.1$ ). When censoring participants for time of death, time of diagnosis, or 31 December 2008, the total number of person-years in the cohort was 49 973. Breast cancer was diagnosed among 97 women between baseline and follow-up. Three of these were excluded because data on the shift work variable were missing.

Table 1 shows characteristics of the three groups at baseline. The two groups of shift workers were younger than the day workers. Nulliparity was more common among shift workers. Smoking was more prevalent among night workers. No significant differences were found regarding BMI, but waist-hip ratio tended to be lower in the two groups of shift workers. Compared to shift workers, a higher proportion of day workers had passed menopause. High alcohol consumption was more prevalent among day workers.

The cumulative incidence in the three groups is shown in table 2. Age at diagnosis was lower in the two groups with shift work, compared with those in the day working group. Shift workers with night work tended to have a shorter time from baseline to diagnosis than day workers.

Results of the Cox regression analysis showed increased HR for shift workers with night work compared with day workers (table 3 ). When analysis was restricted to those women $<60$ years of age, the HR increased further for shifts with night work.

It was possible to calculate the exposure time for night work using responses from those who answered the WOLFU questionnaire [ $\mathrm{N}=341$, mean 9.39 years, standard deviation (SD) 9.53]. It was also possible to compare the information provided in WOLFU with baseline data. Of those who reported that they had had no experience of shift work (with or without night work) in WOLFU, $22 \%$ had reported such experience at 
Table 1. Characteristics of the cohort at baseline. [BMI=body mass index; SD=standard deviation.]

\begin{tabular}{|c|c|c|c|c|c|c|c|c|c|c|c|}
\hline & \multicolumn{9}{|c|}{ Work schedule } & \multirow[t]{3}{*}{ P-value a } & \multirow[t]{3}{*}{ P-value } \\
\hline & \multicolumn{3}{|c|}{ Day $(\mathrm{N}=2511)$} & \multicolumn{3}{|c|}{ Shift without night (N=976) } & \multicolumn{3}{|c|}{ Shift with night ( $N=549)$} & & \\
\hline & Mean & SD & $\%$ & Mean & SD & $\%$ & Mean & $\mathrm{SD}$ & $\%$ & & \\
\hline Age (years) & 43.5 & 10.5 & & 40.9 & 10.6 & & 38.9 & 10.4 & & $<0.001$ & $<0.001$ \\
\hline Educ1 ${ }^{c}$ & & & 37.0 & . & . & 48.5 & & . & 34.8 & $<0.001$ & 0.33 \\
\hline Educ2 d & & . & 59.0 & . & . & 69.1 & & . & 57.5 & $<0.001$ & 0.51 \\
\hline Given birth to $\geq 1$ child & . & 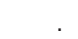 & 74.8 & . & . & 66.3 & & . & 67.5 & $<0.001$ & $<0.001$ \\
\hline Number of children & 1.5 & 1.1 & . & 1.4 & 1.3 & . & 1.5 & 1.3 & . & $<0.001$ & 0.55 \\
\hline Smokers & . & . & & . & . & & & . & & & \\
\hline Current & . & . & 23.7 & . & & 21.9 & & . & 31.0 & 0.24 & $<0.001$ \\
\hline Never & . & . & 49.4 & . & & 49.8 & & . & 47.0 & 0.89 & 0.29 \\
\hline High alcohol intake & & & 30.9 & & & 27.3 & & & 21.4 & 0.06 & $<0.001$ \\
\hline Weight (kg) & 67.1 & 11.1 & . & 66.6 & 10.9 & . & 67.3 & 11.7 & . & 0.30 & 0.64 \\
\hline Height $(\mathrm{cm})$ & 166.1 & 6.0 & . & 166.3 & 6.1 & & 166.1 & 6.1 & . & 0.42 & 0.85 \\
\hline $\mathrm{BMI}(\mathrm{kg} / \mathrm{m} 2)$ & 24.3 & 4.0 & & 24.1 & 3.8 & & 24.4 & 4.0 & & 0.13 & 0.78 \\
\hline$\geq 25$ & . & . & 33.9 & . & & 31.9 & & . & 35.1 & 0.30 & 0.60 \\
\hline$\geq 30$ & & & 10.1 & & & 7.7 & & & 7.2 & 0.053 & 0.85 \\
\hline Waist-hip ratio & 0.79 & 0.07 & & 0.77 & 0.06 & & 0.78 & 0.06 & & $<0.001$ & 0.045 \\
\hline Passed menopause & . & . & 28.0 & . & & 23.1 & & . & 18.9 & 0.003 & $<0.001$ \\
\hline
\end{tabular}

${ }^{a}$ Comparison between day and shift without night.

${ }^{\mathrm{b}}$ Comparison between day and shift with night.

c University or college level.

${ }^{\mathrm{a}}$ High school or higher level.

Table 2. Cumulative incidence of breast cancer, age at diagnosis, and time from baseline to diagnosis. [SD=standard deviation.]

\begin{tabular}{|c|c|c|c|c|c|c|c|c|c|c|c|}
\hline & \multicolumn{9}{|c|}{ Work schedule } & \multirow[t]{3}{*}{ P-value a } & \multirow[t]{3}{*}{ P-value ${ }^{b}$} \\
\hline & \multicolumn{3}{|c|}{ Day } & \multicolumn{3}{|c|}{ Shift without night } & \multicolumn{3}{|c|}{ Shift with night } & & \\
\hline & Mean & SD & $\%$ & Mean & SD & $\%$ & Mean & SD & $\%$ & & \\
\hline Cumulative incidence & & & $2.4(60 / 2511)$ & & & $2.0(20 / 976)$ & & & $2.6(14 / 549)$ & & \\
\hline Age at diagnosis (years) & 57.3 & 7.3 & & 52.1 & 8.9 & & 53.3 & 7.9 & 34.8 & 0.01 & 0.07 \\
\hline Time baseline-diagnosis (years) & 8.4 & 4.4 & & 9.0 & 4.1 & & 6.2 & 2.4 & 57.5 & 0.60 & 0.01 \\
\hline Time baseline-censoring (years) & 12.4 & 3.2 & & 12.3 & 3.3 & & 12.6 & 3.0 & & & \\
\hline
\end{tabular}

${ }^{a}$ Comparison between day and shift without night.

${ }^{\mathrm{b}}$ Comparison between day and shift with night.

baseline. Of those who reported they never had worked shift with night shifts in the WOLFU questionnaire, $2 \%$ reported night shifts at baseline.

\section{Discussion}

This study indicates that shift work with night shifts is associated with an increased risk of breast cancer. This finding is consistent with a number of published epidemiological studies. The adjusted risk was 2.02, which is comparable with that of Davis et al (6) [odds ratio (OR) 2.3, duration of exposure $>4.6$ years], Lie et al (7) (OR 2.21, duration of exposure $\geq 30$ years), and Pesch et al (38) (OR 2.48, duration of exposure $\geq 20$ yrs). Tynes (39) reported higher risk [risk ratio (RR) 3.2, duration of exposure $<3.2$ years and age $>50$ years; risk 4.3 , duration of exposure $>3.2$ years and age $>50$ years]
Hansen (40) found a slightly lower risk compared with our results (OR 1.7, duration of exposure $>6$ years of night work) and Schernhammer (41) (RR 1.79, duration of exposure $\geq 20$ years). In our study, it was not possible to obtain data on the duration of lifetime exposure for all participants, only for those who answered the questionnaire in 2009.

Our results showed that shifts without night work were associated with a HR of 1.23 , which is not statistically significant. Hansen et al (15) did not find any increased risk [OR 0.9, 95\% CI 0.4-1.9] in a Danish case-control study on nurses who worked evening shifts (the shift started in the afternoon and ended at 23:00 or 24:00 hours). A case-control study from the USA showed an OR of 1.08 (95\% CI 0.81-1.44) among evening shift workers (34). The evening shift, however, was a mix of evening and night work, since it started in the afternoon and could end as late as 02:00 hours.

When considering only cumulative incidence, there 
Table 3. Hazard ratio of breast cancer cases. Results of Cox regression analysis. [HR=hazard ratio; $95 \% \mathrm{Cl}=95 \%$ confidence interval.]

\begin{tabular}{ccrl}
\multicolumn{2}{c}{ Model 1 (Crude) } & & \multicolumn{2}{c}{ Model 2 a } \\
$\quad$ HR $\quad 95 \% \mathrm{Cl}$ & & HR $95 \% \mathrm{Cl}$
\end{tabular}

All ages

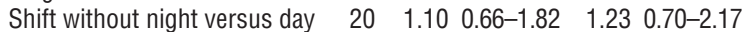

$\begin{array}{llllll}\text { Shift with night versus day } \quad 14 & 1.65 & 0.92-2.95 & 2.02 & 1.03 & -3.95\end{array}$

Ages $<60$ years

Shift without night versus day $\quad \begin{array}{lllll}17 & 1.05 & 0.63-1.75 & 1.18 & 0.67-2.07\end{array}$

\begin{tabular}{|c|c|}
\hline Shift with night versus day & 12 \\
\hline
\end{tabular}

${ }^{a}$ Adjusted for number of children (4 levels) and alcohol consumption (high/low).

were only marginal differences between the three work schedules. However, the shift workers with night shifts were younger at inclusion and diagnosed with breast cancer earlier than the day workers. The time between baseline and diagnosis was significantly shorter among those who worked shifts with night work than those who worked days only. This might indicate that the tumor progression was faster among night shift workers. When we included only women $<60$ years of age, the HR increased further for those who had worked shifts with night work. This indicates that the lag between exposure and cancer is not very long and supports the hypothesis that shifts with night work is a causal factor.

Inconsistencies in previous research on night work and cancer can be due to a poor definition of the shift work variable. One null study used a definition based on occupation (42). Those who had a job title corresponding to an occupation with an estimated prevalence of $\geq 40 \%$ of shift workers, according to the Swedish Survey of Living Conditions, were defined as shift workers. The negative results in that study could be due to misclassification of the exposure. Given that the misclassification is nondifferential, it will bias the effect estimate towards null. Another negative study asked for exposure to shift work only for the last 15 years, which probably led to misclassification of shift workers with a longer exposure time or exposure to shift work further back in time (34). Our finding that those who worked shifts with nights were diagnosed with breast cancer at a younger age, and that the time between baseline and diagnosis was shorter could have a bearing on this issue. One might hypothesize that some women have increased vulnerability due to genetic differences or behavioral factors. When they are exposed to shift work, cancer might develop early.

There are a number of risk factors for breast cancer suggested in the literature: age at birth of first child, number of children, obesity, use of contraceptive pills, hormone treatment, nulliparity, smoking, alcohol consumption, and short time of breast feeding $(43,44)$. We tested potential confounding by entering contraceptive pills, other hormonal treatment, menopausal status, obesity, number of children, smoking (ever and current), alcohol intake, and educational level into the analyses. Number of children and frequent alcohol intake changed the regression coefficient for shift work, and were therefore included in the final model. Yet, even if many potential confounders have been adjusted for, there may still be others not considered in the present study. Among them could be be age of first exposure to shift work. Also exposure before or after menopause could be an interesting factor, but such data were not available.

The present study has several other limitations that are common in most studies. Reliance on self-reported exposure can involve anamnestic mistakes. Our data showed that if people are asked for past experience of shift work, the information given will be affected by difficulties in correctly recalling previous exposure. Of those who reported no experience of shift work in the final follow-up, $22 \%$ actually had reported current exposure to shift work at baseline. The agreement between information given at baseline and follow-up, however, was better when considering shift work with night shifts. Of those who reported no experience of night shift work at follow-up, only $2 \%$ reported night work at baseline. It appears that retrospective information about night shift experience is more reliable than information about shifts without night work. In $53 \%$ of the subjects, we had retrospective information about lifetime exposure to shift work (with and without night work), in $36 \%$ we had only baseline information. The baseline questionnaire provided information only on current shift work/ night work, and it is probable that some subjects, who were classified as day workers based on this information only, were actually former shift workers. However, it is not possible to draw any conclusions about how this misclassification could have biased our results.

Another issue is the size of the study; a larger number of participants may have yielded clearer results in some of the analyses. A strength of the present study is the longitudinal, prospective cohort design. In the literature, we found only three prospective cohort studies on the association between shift work and breast cancer. Two were positive $(5,41)$ and one was negative (13). The majority of published studies have been case-control studies in which possible recall bias limits the validity of exposure information. The unique person identification number available for all Swedish citizens makes it possible to obtain almost complete data from the Swedish cancer registry on cancer incidence during follow-up. Another advantage is that we had access to information on several potential confounding factors that we could take into account in the analyses.

There are a number or biological mechanisms that could explain the increased risk for cancer among shift workers but today we cannot say which mechanism is most plausible $(12,45)$. In order to try preventive 
measures, it is necessary to elucidate the mechanism behind the increased cancer risk. If the melatonin suppression is the crucial factor, one preventive method could be to reduce exposure to LAN (46). It would also be possible to use only red light at night, because red light does not interfere with melatonin production. If the major problem is the challenge of the circadian rhythm or interaction between night work and genetic predisposition, other preventive measures should be evaluated (46).

In conclusion, we found an increased risk of breast cancer among shift workers who have had night work in their schedule. Shift workers who did not have night work had a small and statistically insignificant risk compared with day workers. Our finding supports previous research reporting an increased breast cancer risk among night shift workers. However, we cannot rule out that also shift workers without night work are at a higher risk of cancer than day workers.

\section{Ethics}

The Regional Research Ethics Board in Stockholm and the ethics committee at Karolinska Institutet, Stockholm, Sweden, approved the study.

\section{References}

1. Costa G. Shift work and occupational medicine: an overview. Occup Med. 2003;53:83-8. http://dx.doi.org/10.1093/ occmed/kqg045.

2. European Foundation for the Improvement of Living and Working Conditions. European Working Conditions Survey, 2010.

3. Wang XS, Armstrong MEG, Cairns BJ, Kay TJ, Travis RC. Shift work and chronic disease: the epidemiological evidence. Occup Med. 2011;61:78-89. http://dx.doi.org/10.1093/ occmed/kqr001.

4. International Agency for Research on Cancer. IARC monographs on the evaluation of carcinogenic risks to humans. Painting, firefighting, and shiftwork. Lyon: International Agency for Research on Cancer; 2010. p563-766.

5. Schernhammer ES, Laden F, Speizer FE, Willett WS, Hunter DJ, Kawachi I, et al. Rotating night shifts and risk of breast cancer in women participating in the Nurses' Health Study. J Natl Cancer Inst. 2001;93:1563-8. http://dx.doi.org/10.1093/ jnci/93.20.1563.

6. Davis S, Mirick DK, Stevens RG. Night shift work, light at night, and risk of breast cancer. J Natl Cancer Inst. 2001;93:1557-62. http://dx.doi.org/10.1093/jnci/93.20.1557.

7. Lie JA, Roessink J, Kjæheim K. Breast cancer and night work among Norweigan nurses. Cancer Causes Control. 2006;17:39 44. http://dx.doi.org/10.1007/s10552-005-3639-2.

8. Kubo T, Ozasa K, Mikami K, Wakai K, Fujino Y, Watanabe
Y, et al. Prospective cohort study of the risk of prostate cancer among rotating-shift workers: findings from the Japan Collaborative Cohort Study. Am J Epidemiol. 2006;164:549 55. http://dx.doi.org/10.1093/aje/kwj232.

9. Viswanathan AN, Hankinson SE, Schernhammer ES. Night shift work and the risk of endometrial cancer. Cancer Res. 2007;67:10618-22. http://dx.doi.org/10.1158/0008-5472. CAN-07-2485.

10. Schernhammer ES, Laden F, Speizer FE, Willett WS, Hunter DJ, Kawachi I, et al. Night-shift workers and the risk of colorectal cancer in the nurses' health study. J Natl Cancer Inst. 2003;95:825-8. http://dx.doi.org/10.1093/jnci/95.11.825.

11. Lahti TA, Partonen T, Kyyrönen P, Tauppinen T, Pukkala E. Night-time work predisposes to non-Hodgkin lymphoma. Int J Cancer. 2008;123:2148-51. http://dx.doi.org/10.1002/ ijc. 23566 .

12. Costa G, Haus E, Stevens R. Shift work and cancer considerations on rationale, mechanisms, and epidemiology. Scand J Work Environ Health. 2010;36:163-79. http://dx.doi. org/10.5271/sjweh.2899.

13. Pronk A, Ji BT, Shu XO, Xue S, Yang G, Li HL, et al. Nightshift work and breast cancer risk in a cohort of Chinese women. Am J Epidemiol. 2010;171:953-9. http://dx.doi. org/10.1093/aje/kwq029.

14. Lie JA, Kjuus H, Zienolddiny S, Haugen A, Stevens RG, Kjæheim K. Night work and breast cancer risk among Norweigan nurses: assessment by different exposure metrics. Am J Epidemiol. 2011;173:1272-9. http://dx.doi. org/10.1093/aje/kwr014.

15. Hansen J, Stevens RG. Case-control study of shift-work and breast cancer risk in Danish nurses: Impact of shift systems. Eur J Cancer. 2012;48:1722-9. http://dx.doi.org/10.1016/j. ejca.2011.07.005.

16. Hansen J, Lassen CF. Nested case-control study of night shift work and breast cancer risk among women in the Danish military. Occup Environ Med. 2012;69:551-6. http://dx.doi. org/10.1136/oemed-2011-100240.

17. Atwood A, DeConde R, Wang SS, Mockler TC, Sabir JS, Ideker T, et al. Cell-autonomous circadian clock of hepatocytes drives rhythms in transcription and polyamine synthesis. Proc Natl Acad Sci USA. 2011;108:18560-5. http://dx.doi. org/10.1073/pnas.1115753108.

18. Sancar A, Lindsay-Boltz LA, Kand TH, Reardon JT, Lee JH, Ozturk N. Circadian clock control of the cellular response to DNA damage. FEBS Lett. 2010;584:2618-25. http://dx.doi. org/10.1016/j.febslet.2010.03.017.

19. Lee JH. Sancar A. Regulation of apoptosis by the circadian clock through NF-kappa B signaling. Proc Natl Acad Sci USA. 2011;108:12036-41. http://dx.doi.org/10.1073/ pnas. 1108125108 .

20. Greene MW. Circadian rhythms and tumor growth. Cancer Letters. 2012;318:115-23. http://dx.doi.org/10.1016/j. canlet.2012.01.001.

21. Filipski E, Innominato PF, Wu M, Li XM, Iacobelli S, Xian LJ, et al. Effects of light and food schedules on liver and tumor 
molecular clocks in mice. J Natl Cancer Inst. 2005;97:507-17. http://dx.doi.org/10.1093/jnci/dji083.

22. Stevens RG. Light-at-night, circadian disruption and breast cancer: assessment of existing evidence. Int $\mathrm{J}$ Epidemiol. 2009;38:963-70. http://dx.doi.org/10.1093/ije/dyp178.

23. Cos S, Mediavilla D, Martinez-Campa C, Gonzales C, A, Alonso-Gonzalez C, Sanchez Barcelo EJ. Exposure to lightat-night increses the growth of DMBA-induced mammary adenocarcinoma in rats. Cancer Lett. 2006;235:266-71. http:// dx.doi.org/10.1016/j.canlet.2005.04.025.

24. Zhu Y, Stevens RG, Hoffman AE, Tjonneland A, Vogel UB, Zheng T, et al. Epigenetic impact of long-term shiftwork: Pilot evidence from circadian genes and whole-genome methylation analysis. Chronobiol Int. 2011;28:852-61. http://dx.doi.org/1 $0.3109 / 07420528.2011 .618896$.

25. Hoffman AE, Yi CH, Zheng T, Stevens RG, Leaderer D, Zhang Y, et al. CLOCK in breast tumorigenesis: genetic, epigenetic, and transcriptional profiling analyses. Cancer Res. 2010;70:1459-68. http://dx.doi.org/10.1158/0008-5472. CAN-09-3798.

26. Arendt J. Melatonin and human rhythms. Chronobiol Int. 2006;23:21-37. http://dx.doi.org/10.1080/07420520500464361.

27. Blask DE, Brainard GC, Dauchy RT, Hanifin JP, Davidson LK, Krause JA, et al. Melatonin-depleted blood from premenopausal women exposed to light at night stimulates growth of human breast cancer xenografts in nude rats. Cancer Res. 2005;65:11174-84. http://dx.doi.org/10.1158/00085472.CAN-05-1945.

28. Hardeland R. Melatonin, hormone of darkness and more: occurrence, control mechanisms, actions and bioactive metabolites. Cell Mol Life. 2008;65:2001-18. http://dx.doi. org/10.1007/s00018-008-8001-x.

29. Erren TC, Reiter RJ. Defining chronodisruption. J Pineal Res. 2009;46:245-7. http://dx.doi.org/10.1111/j.1600079X.2009.00665.x.

30. Schernhammer ES, Hankinson SE. Urinary melatonin levels and breast cancer risk. J Natl Cancer Inst. 2005;97:1084-7. http://dx.doi.org/10.1093/jnci/dji190.

31. Travis RC, Allen DS, Fentiman IS, Key TJ. Melatonin and breast cancer: a prospective study. J Natl Cancer Inst. 2004;96:475-82. http://dx.doi.org/10.1093/jnci/djh077.

32. Borugian MJ, Gallagher RP, Friesen MC, Switzer TF. Aronson KJ. Twenty-four-hour light exposure and melatonin levels among shift workers. J Occup Environ Med. 2005;47:1268-75. http://dx.doi.org/10.1097/01.jom.0000184855.87223.77.

33. Schernhammer ES, Berrino F, Krogh V, Secreto G, Mitchell A, Venturelli E, et al. Urinary 6-sulfatoxymelatonin levels and risk of breast cancer in postmenopausal women. J Natl Cancer Inst. 2008;100:898-905. http://dx.doi.org/10.1093/ jnci/djn171.

34. O'Leary ES, Schoenfeld ER, Stevens RG, Kabat GC, Henderson K, Grimson R, et al. Shift work, light at night, and breast cancer on Long Island, New York. Am J Epidemiol. 2006;164:358-66. http://dx.doi.org/10.1093/aje/kwj211.
35. Alfredsson L, Hammar N, Fransson E, de Faire U, Hallqvist $\mathrm{J}$, Knutsson A, et al. Job strain and major risk factors for coronary heart disease among employed males and females in a Swedish study on work, lipids and fibrinogen. Scand J Work Environ Health. 2002;28:238-48. http://dx.doi.org/10.5271/ sjweh.671.

36. Barlow L, Westergren K, Holmberg L, Talbäck M. The completeness of the Swedish Cancer Register - a sample survey for year 1998. Acta Oncologica. 2009;48:27-33. http:// dx.doi.org/10.1080/02841860802247664.

37. Korn EL, Graubard BI, Midthune D. Time-to-event analysis of longitudinal follow-up of a survey: choice of the time-scale. Am J Epidemiol. 1997;145:72-80. http://dx.doi.org/10.1093/ oxfordjournals.aje.a009034.

38. Pesch B, Harth V, Rabstein S, Baisch C, Schiffermann M, Pallapies D, et al. Night work and breast cancer - results from the German GENICA study. Scand J Work Environ Health. 2010;36:134-41. http://dx.doi.org/10.5271/sjweh.2890.

39. Tynes T, Hannevik M, Andersen A, Vistnes AI, Haldorsen T. Incidence of breast cancer in Norwegian female radio and telegraph operators. Cancer Causes Control. 1996;7:197-204. http://dx.doi.org/10.1007/BF00051295.

40. Hansen J. Increased breast cancer risk among women who work predominantly at night. Epidemiology. 2001;12:74-7. http://dx.doi.org/10.1097/00001648-200101000-00013.

41. Schernhammer ES, Kroenke CH, Laden F, Hankinson SE. Night work and risk of breast cancer. Epidemiology. 2006;17:108 11. http://dx.doi.org/10.1097/01.ede.0000190539.03500.c1.

42. Schwartzbaum J, Ahlbom A, Feychting M. Cohort study of cancer risk among male and female shift workers. Scand J Work Environ Health. 2007;33:336-43. http://dx.doi. org/10.5271/sjweh.1150.

43. Parkin DM. Cancers attributable to reproductive factors in the UK in 2010. Br J Cancer. 2011;105:S73-S76. http://dx.doi. org/10.1038/bjc.2011.488.

44. Parkin DM, Boyd L, Walker LC. The fraction of cancer attributable to lifestyle and environmental factors in the UK in 2010. Br J Cancer. 2011;105:S77-S81. http://dx.doi. org/10.1038/bjc.2011.489.

45. Fritschi L, Glass DC, Heyworth JS, Aronson K, Girschik J, Toyle T, et al. Hypotheses for mechanisms linking shiftwork and cancer. Medical Hypotheses. 2011;77:430-36. http:// dx.doi.org/10.1016/j.mehy.2011.06.002.

46. Bonde JP, Hansen J, Kolstad HA, Mikkelsen S, Olsen JH, Blask DE, et al. Work at night and breast cancer - report on evidence-based options for preventive actions. Scand J Work Environ Health. 2012;38:380-390. http://dx.doi. org/10.5271/sjweh.3282

Received for publication: 23 April 2012 